\title{
Study on The Tribology Characteristic of The Steel-cast Iron Friction Pair in The Self-repairing Additive
}

\author{
Yanhong Yan ${ }^{1, a}$,Xiaoting Shi ${ }^{2, b}$, Yanhong Xia ${ }^{3, c}$ and Xuchao Chen ${ }^{4, d}$ \\ ${ }^{1}$ College of mechanical engineering, yanshan university, qinhuangdao, china \\ ${ }^{2}$ College of mechanical engineering, yanshan university, qinhuangdao, china \\ ${ }^{3}$ College of mechanical engineering, yanshan university, qinhuangdao, china \\ ${ }^{4}$ College of mechanical engineering, yanshan university, qinhuangdao, china \\ ayhyan@ysu.edu.cn, ${ }^{b} 793365990 @ q q . c o m,{ }^{c} 1249719003 @ q q . c o m,{ }^{d} 1031253392 @ q q . c o m$
}

Keywords: steel-cast iron friction pair; self-repairing Additive; loads; frictional wear characteristics;mechanism analysis

Abstract:Influence and mechanism of frictional wear characteristics of $45^{\#}$ steel-cast iron friction pair were investigated under the $46^{\#}$ machine oil that includes the self-repairing additive condition with different loads by using MMU-5G end-face friction and wear testing machine. The capability of generating self-repair coatings on the $45^{\#}$ steel friction surface were verified in the self-repairing additive, frictional wear characteristics of cast iron were investigated specially. The surface images of friction pair and their chemical composition were detected by using SEM and EDS. The result indicates different loads has a great influence on frictional wear characteristics of $45^{\#}$ steel-cast iron pair in the self-repairing additives. For the steel-cast iron friction pair in the self-repairing additive, the Self-repair coatings are formed on the 45\#steel worn surface with the load of $500 \mathrm{~N}$ and the relative sliding speeds of $0.553 \mathrm{~m} / \mathrm{s}$, Although there were no Self-repair coatings on the cast iron worn surface,additive has remarkable effect on antifriction and wearing of cast iron.

\section{Introduction}

Wear is one of the three main forms (wear, corrosion, fatigue fracture) of material failure; it is a major reason that reduces the efficiency and accuracy of machines, indeed make the machines retirement. Therefore, it is particularly urgent and important to improve the existing part's life and repair the worn parts to achieve saving materials, reducing energy consumption and enhancing economic efficiency.

Metal wear self-repairing technology uses mineral powder lubricant composition, and the energy condition that provided by friction system to prompt friction chemical, electrochemical, mechanical-chemical and force chemical reaction adequately between metal wear self-repairing additive and the contact surface materials of friction pair, in order to achieve the online self-repair on micro-worn surface dynamically. In recent years, the metal self-repairing additive has been studied more extensively [2-4]. Experimental resultsthat hydroxide radical magnesium silicate mineral powder additives do have good self-repairing properties[5-7],so the frictional wear characteristic of each friction pair in the self-repairing additive has been studied more extensively, and great progresses have been made on the research of analyzing the self-repairing mechanism[8-10]. Metal wear self-repairing technology has made remarkable achievements in practical application, but asconditions and mechanism of self-repairing coatings' conformation have not been fully recognized, the promotion and application of the technology is limited.

Load is an important characterization of the tribological system characteristics. Gao et al., using MM2200 friction and wear testing machine, studied the forming progress and mechanism of the coatings on the metal surface of steel-steel friction pairing under the silicate additive conditions with different loads. The results showed that the formation of the self-repairing film induced by the silicate additives was highly influenced by friction energy. The composition of the self-lubricating film was ceramic oxides which was mainly originated from the silicate additives [11].Garbar investigated the applied load on the wear of materials of a friction pair consisting of low-carbon 
steel and copper. The results revealed a critical pressure value of 3.3MPa which divided "mild" (lower pressure) and "severe" (higher pressure) wear. Also, both steel and copper was harden under all applied pressures and this was believed to be highly connected with the wear mechanisms [12] .

Due to the current researches in this field focus on the steel - steel pairs, there are few study and related reports about the frictional wear characteristics of cast iron in self-repairing additive are very little. In view of this, the author make a series of studies of frictional wear characteristics of cast iron in the home-made hydroxide silicate lubricant additive, this paper investigatesinfluence and mechanism of frictional wear characteristics of $45 \#$ steel-cast iron friction pair under the $46 \#$ machine oil that includes the self-repairing additive condition with different loads.

\section{Test Part}

Self-repairing Additive. The additive used in the test is hydroxide radical magnesium silicate (serpentine), Equipment used is the GN-2 high-energy globe mill. After milled, the size of powder particle of additives is around $200 \mathrm{~nm}$.

Tribology Experiment. The experiments of tribology used MMU-5G screen-ending-face friction and wear test machine. The upper specimen is ordinary cast iron (HT200); and the under specimen is $45 \#$ steel. Self-repairing additive is $2 \%$, at room temperature, friction and wear experimental time is 24 hours, additive is scattered for $20 \mathrm{~min}$ in $46 \#$ mechanical oil by ultrasonic, lubricated with oil pool. Before and after the experiment, all specimens should be cleaned for 15 min by ultrasonic in the acetone solution. After dried in the atmosphere, the mass of the specimen should be measured by the sensor electronic scales whose precision is $0.1 \mathrm{mg}$. In the experiment, the impact of load on friction and wear characteristics is studied with rotational speed of $346 \mathrm{r} / \mathrm{m}$ (the relative sliding speed of $0.415 \mathrm{~m} / \mathrm{s}$ ). The worn surface and cross-section of the specimen are observed by the new field emission scanning electron microscopy (SEM), the sample surface composition is tested by EDS.

\section{Test results and analysis}

\section{The influence of friction and wear properties.}

The impact of mass loss.Figure. 1 is the wear mass loss curve of upper and under samples under different loads conditions. It can be seen from the figure, the change of loads has little effect on mass loss. Mass loss increased slowly when the load changes from $100 \mathrm{~N}$ to $300 \mathrm{~N}$, then decreased slowly, the change of the curve is very little; but it has very significant effect on specimens of 45\# steel. When the applied load is small $(100 \mathrm{~N} \sim 300 \mathrm{~N})$, the wear mass loss of under specimen grows slowly, there is not a lot of wear mass loss, when the load is larger $(300 \mathrm{~N} \sim 500 \mathrm{~N})$, the mass wear of under sample changes very obviously, when the load is $400 \mathrm{~N}$, the mass loss achieves the maximum, and when the large number of wear mass loss appears, the wear mass loss curve decreases significantly.

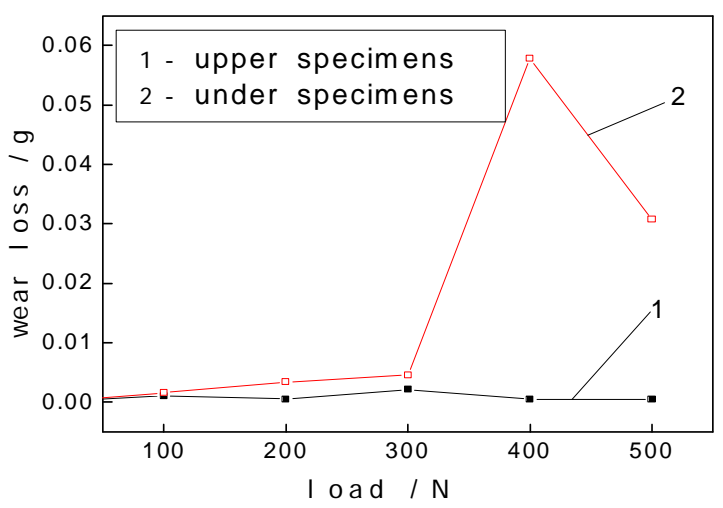

Fig. 1. Wear mass loss of samples in different loads conditions 
Influence of friction coefficient.Figure.2shows the coefficient curve under different loads conditions.It can be seen from Fig.2, loads impact the friction coefficient very obviously.

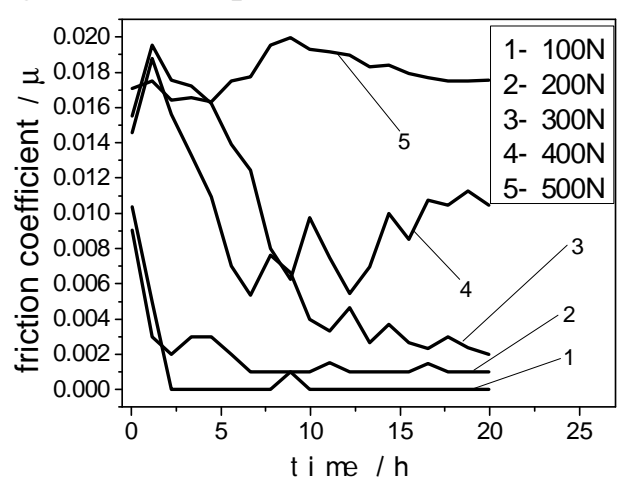

Fig. 2. The curve of Friction coefficient under different loads

SEM observation of worn surface and EDS test. Figure. 3 shows the SEM photographs of worn surface of cast iron with different loads in the end of the experiment. With the load of $100 \mathrm{~N}$, the surface has a small amount of scratches and furrows, there is no spalling basically; with the load of $200 \mathrm{~N}$, the sample surface has more scratches and furrows, but also no significant peeling; with the load of $300 \mathrm{~N}$, the friction surface has more many scratches, furrows, and many local peeling; with the load of $400 \mathrm{~N}$, the sample surface has visible scratches and furrows, and spalling is more serious; with the load of $500 \mathrm{~N}$, the sample surface has visible scratches, spalling is serious, larger areas of flaking appear.
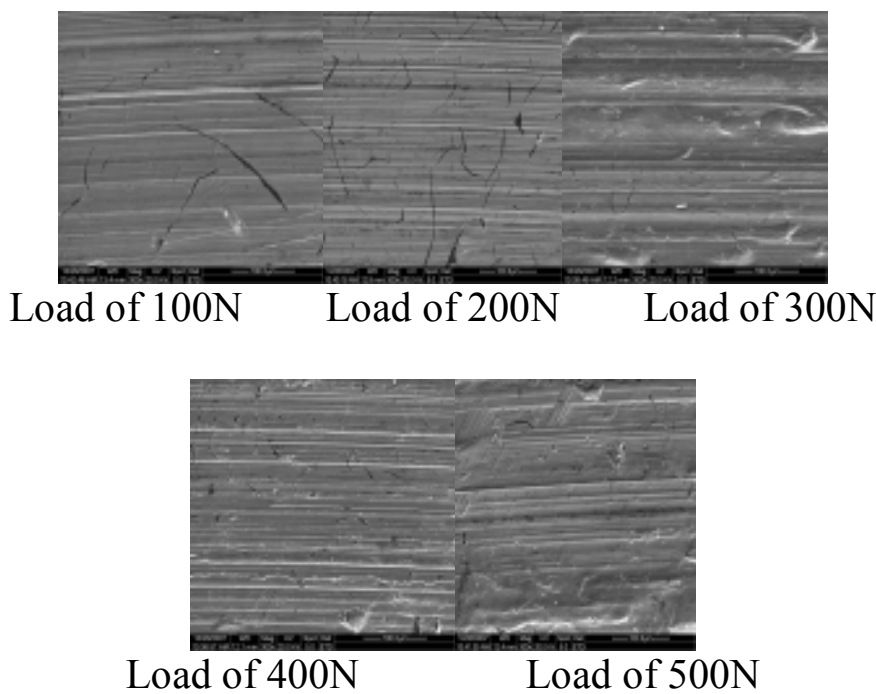

Fig. 3. SEM photographs of worn surface of cast iron under different loads (for grinding 24h)

Figure. 4 is the EDS photos of worn surface of cast iron with and without additives. Experiments show that the two energy spectra images are basically the same, but the contents of $\mathrm{C}$ and $\mathrm{O}$ are slightly higher on the friction surface under additives, after analysis, it is believed that $\mathrm{C}$ and $\mathrm{D}$ come from the decomposition of lubricating oil and Mg21Si12O28 (OH) $34 \cdot \mathrm{H} 2 \mathrm{O}$, which is the main component of self-repairing additives. The specimen surface was not found to have main component of repair material, the $\mathrm{Mg}$ and Si elements.

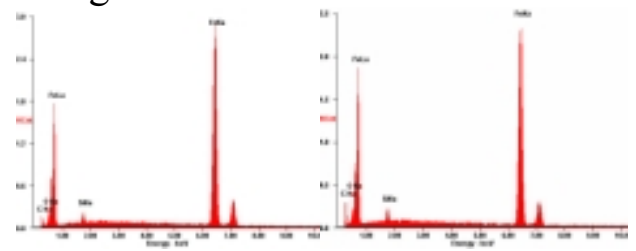

(a) Without additive

(b) $2 \%$ additive

Fig. 4. EDS images of surface of cast iron under different lubrication conditions 
Studies have shown that friction modification layers or self-repairing coatings can be generated on the friction surface of the steel-steel friction pair under the metal self-repairing additives conditions [13-15]. This experimental result shows that when 45\# steel matches with cast iron, the self-repairing coatings can still be generated on the 45\# steel friction surface. Through observing SEM photographs of samples with different loads by scanning electron microscopy, it can be seen that under certain operating conditions, there is a thin layer of material that combines with substrate well on the 45\# steel substrate, as shown in Fig.5 (a). The corresponding energy spectra (d) also displays that this layer contains $\mathrm{Mg}$ and $\mathrm{Si}$ elements, they are included in the main body of self-repairing additives, it shows a self-repairing response occurs during the friction wear progress; and comparing spectrum (c) and (d) of cast iron with Fig.4 (a) under the same working conditions, there are no external elements on the surface.

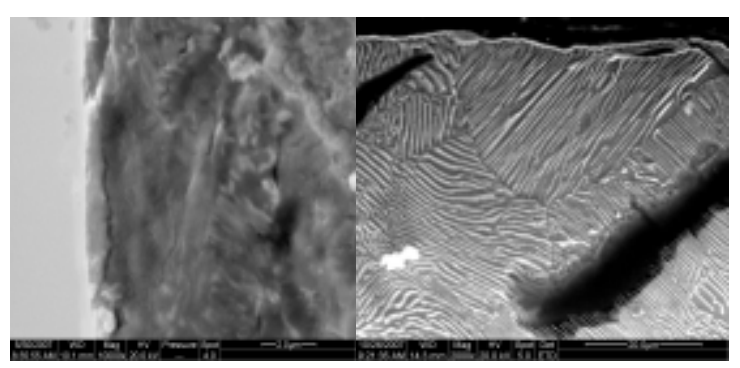

(a) $45^{\#}$ steel

(b) Cast iron

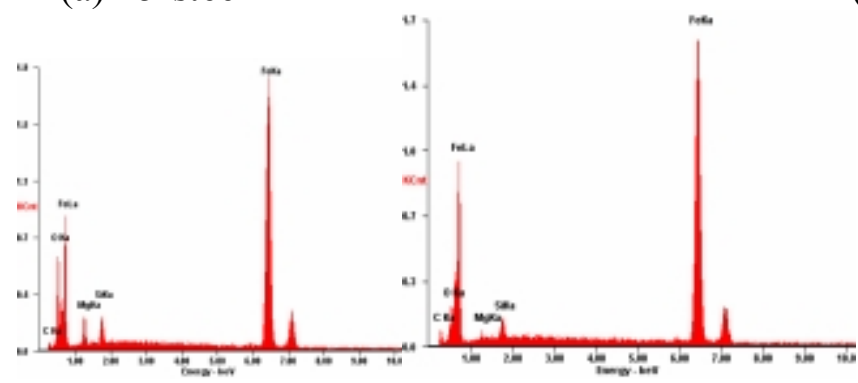

(c). EDS images corresponding (a)

(d). EDS images corresponding (b)

Fig. 5. SEM images of cross-section of samples and the corresponding energy spectrum Photos

Mechanism Analysis.From analyzing the wear mass curves with different loads (Fig. 1), it can be founded that the mass loss of the specimens is larger in the initial running, the reason for this is that the original samples' surface is rough after line-cutting, in the initial experiment, burr is worn away. With load of $400 \mathrm{~N}$, the load is too large, samples' wear and tear is severe, the wear mass loss increases suddenly; with load of $500 \mathrm{~N}$, from the energy spectra of under sample (Fig. 6), it can be seen, the surface of $45 \#$ steel has main elements of additives, it indicates that repair materials particulate be squeezed into the concaves and pores, the energy released by friction of the steel and cast iron samples is enough to stimulate friction chemical and electrochemical reaction, with instantaneous high temperature and pressure generated in the local contact area on friction surface, micro-sintering and micro-metallurgical process occur, a layer of metal-ceramic repairing coating is formed on the surface of friction pair, it expresses as the increases of quality.

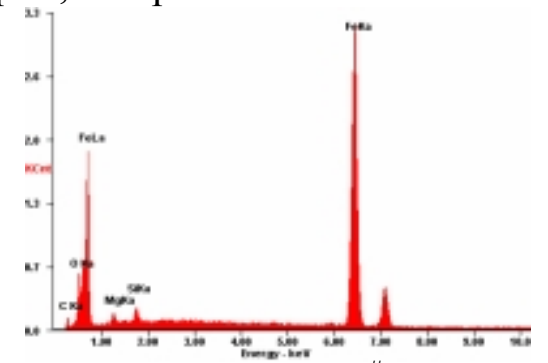

Fig. 6. EDS images of surface of $45^{\#}$ steel with load of $500 \mathrm{~N}$ 
Due to graphite exists in cast iron as the lamellar crystal structure, when friction pair slide, the graphite on the surface is a good solid lubricant, at the same time, can absorb and preserve oil, holes will form after graphite falling off the metal substrate, and they can also save the lubricant, and promote the formation of lubricant film, thereby the wear of cast iron surface reduces, so the wear quality of cast iron is bound to be less than $45 \#$ steel.

Generally, it is considered that the strength of cast iron is lower than steel, its surface is more easily to be destroyed and exposed, in the case that high temperature and pressure, namely "flash temperature", continue to occur, it would be easier to generate self-repairing protective layer, but this experiment proves that self-repairing film does not generate on the worn surface of cast iron. The analysis considers that the key to form self-repairing protective films on metal worn surface is the occurrence of micro-metallurgical reactions, due to the microstructure and mechanical performance of cast iron, when the loads are small, a thick graphite ball membrane is easy to be formed on the surface of cast iron, and it blocks the repair material particles to enter into the friction surface; when the loads increase, although the graphite globule membrane is destroyed, but because the cast iron's strength and hardness are low, the additive particles are easy to cutting out cast iron after they are embedded in cast iron surface, the additive particles are taken away by the cast iron filings under higher loads conditions, the additive particles are difficult to remain in the cast iron base, there is no sufficient time to occur micro-metallurgical process, therefore, it is difficult to form a self-repairing coating on the friction surface of cast iron.

The effect of antifriction and antiwear is notable under suitable amount of additives condition, the analysis considers that it because of the physical effect of additive particles. After additives are applied in the friction pair, they are continued to be smashed to tiny particles under the pressure and shear force that exist between the friction pair, the motion on the friction surface is relatively easy to scroll, especially the powders that are close to the spherical and rod-shaped can play the role of Micro-balls, they can change sliding friction into rolling friction between friction pair, and reduce the friction coefficient; particles have micro-grinding effect on actual contact spots of the surface of friction pairs, make them smooth, reduce friction and wear. Thus, though there is no self-repairing protective coating generated on the friction surface of cast iron, but additives improve antifriction and anti-wear significantly.

\section{Conclusions}

1.Different loads have a great influence on frictional wear characteristics of $45 \#$ steel-cast iron pair. Loads have greater impact on the wear incremental loss, the friction coefficient of friction pair increases as the load increasing;

2. When load is too small, the energy released by friction effect of friction pair is not enough to stimulate friction chemical reaction; when 45\# steel matches with cast iron, there are self-repairing protective coatings generated on the surface with load of $500 \mathrm{~N}$.

3. Though there is no self-repairing protective coating generated on the friction surface of cast iron, but additives improve antifriction and antiwear significantly.

\section{References}

[1] Y. Qi, Friction and Wear, High Education Press, Beijing, 1986. (In Chinese)

[2] B. Zhang, B. Xu, Y. Xu. Y. Wu,B. Zhang, Friction Reduction and Anti-wear Mechanism of Serpentine Micro-powders for Spheroidal Graphite Iron Tribo-pair, Journalof The ChineseCeramic Society. 37(12) (2009) 2037-2042. (In Chinese)

[3] L.Y.Dai, R.G.Meng, J.F.Chen, Y.J.Wang, D.Wang, The research progress of metal wear self-repair nanoparticles, China Shiprepair. 25(4) (2012)33-35. (In Chinese) 
[4]B. Tian, C.B. Wang, Y.H. Gu, W. Yue, X.D. Ma, J.J. Liu, Effect of a cermet additive in lubricating oil on tribological performance of steel/steel friction pair,Transactionsof Materials And HeatTreatment.27(3) (2006)132-136. (In Chinese)

[5] W.G. Chen, Y.Z. Gao, H.C. Zhang, Z.F.Tan, Self-repairing Characteristics of Superfine Powder of Hydroxyl Magnesium Silicate On a Worn Steel Surface, Journal of the Chinese ceramic society.38(4) (2010)762-767. (In Chinese)

[6] Q. Liu, Q.Y. Chang, Y.P. Du, Y.S. Jin, Research Progress of Hydroxyl Silicate as Self-repairing Lubricating Oil Additive,Bulletin of The Chinese Ceramic Society.30(4) (2011)840-844. (In Chinese)

[7]G.Z. Zhu, Y.Z. Gao, S.Y. Liu, H.C. Zhang,Antiwear and Self- repairing Mechanisms of Magnesium Hydroxysilicate Composite Powder as a Lubricating Oil Additive for Steel- Steel Pair, Tribology. 32(2) (2012)183-188. (In Chinese)

[8] Y.H.Ma, H.W. Yang, S.L. Yang, T. Yao, Z.L. Li, Development Status of Friction and Wear Lubricant Additivewith Self-remediation Function, Guangzhou Chemical Industry.41(7) (2013)32-33. (In Chinese)

[9] J. Xu, Y. Zhao, H. Cao, Study on The Tribology Characteristic of New Self -compensation Additive, Materials Protection. 33(7) (2000)44-46. (In Chinese)

[10] X. Qi, Y. Yang, F. Xue, Influence and mechanism of the formation of self-repair coatings on metal surface under different contact stress and relative sliding speed, Lubrication Engineering. (7) (2007)20-25. (In Chinese)

[11]Y. Gao, H. Zhang, X. Xu, Formation Mechanism of Self-repair Coatings 0n the Worn Metal Surface Using Silicate Particles as Lubricant 0il Additive, Lubrication Engineering. (10) (2006) 39-42. (In Chinese)

[12]I.I.Garbar, The effect of load on the structure and wear of friction pair materials (example of low-carbon steel and copper). Wear. 205(1997) 240-245.

[13] X. Qi, Z. Jia, H. Chen, Y. Yang, Z. Wu, Self-repairing characteristics of serpentine mineral powder as an additive on steel-chromium plating pair under high temperature, Tribology Transactions. 56(3) (2013) 516-520.

[14] X. Qi, Z. Jia, Q. Yang, Y. Yang, Effects of vanadium additive on structure property and tribological performance of high chromium cast iron hardfacing metal, Surface \& Coatings Technology. 205(23) (2011) 5510-5514.

[15] X. Qi, Z. Jia, Y. Yang, B. Fan, Characterization and auto-restoration mechanism of nanoscale serpentine powder as lubricating oil additive under high temperature, Tribology International. 44(7-8) (2011) 805-810. 